\title{
DESAIN OTOMATISASI PINTU GERBANG FAKULTAS TEKNIK UMJ MENGGUNAKAN RFID ATAU PASSWORD DENGAN SENSOR LASER DIODA
}

\author{
Aji Brahma Nugroho, Fitriana, Ahmad Sugianto \\ Teknik Elektro, Universitas Muhammadiyah Jember, Jln. Karimata No.49 Jember 68121 \\ (tlp: 0331-226728; fax: 0331-337957); \\ e-mail: fitriana@unmuhjember.ac.id
}

\begin{abstract}
ABSTRAK
Abstrak — Pada penelitian ini, telah dibuat Desain Otomatisasi Pintu Gerbang Fakultas Teknik UMJ menggunakan RFID atau Password dengan Sensor Laser Dioda. Frekuensi radio dimanfaatkan untuk membaca informasi dari RFID tag atau transponder (Transmitter Responder) yang disingkat menjadi ID tag yang akan membuka pintu gerbang, sedangkan sensor laser dioda disini sebagai pendeteksi mobil, jika kendaraan memutuskan cahaya sensor laser dioda maka pintu gerbang akan tertutup. alat ini cocok diaplikasikan untuk daerah Fakultas Teknik yang dimana didalamnya dibutuhkkan keamanan dan kenyamanan akses masuk kewilayah tersebut sehingga suasana dapat terjalin dengan tenang dan teratur.Analisis pengujian Dari hasil pengujian RFID, Password dan LCD pada rangkaian didapatkan hasil bahwa apabila Tag RFID didekatkan pada RFID Reader, sama hal dengan password. Tag RFID dan kode password tersebut adalah sesuai yang dimasukan ke dalam program mikrokontroller ATmega8535, maka mikrokontroller ATmega8535 akan memerintahkan Driver Motor untuk menggerakan motor DC untuk bergerak searah jarum jam atau dalam aplikasinya gerbang akan membuka. Apabila kendaraan telah melewati batas gerbang dan memutus sinar laser maka secara otomatis sensor akan mendapatkan nilai hight sehingga pintu gerbang akan menutup.
\end{abstract}

Kata kunci: RFID, ATmega8535, LCD, Motor DC, Keypad

Copyright $@$ C 2019Universitas Muhammadiyah Jember.

\section{PENDAHULUAN}

Kemajuan IPTEK (Ilmu Pengetahuan Dan Teknologi) telah banyak dimanfaatkan dan dirasakan oleh banyak masyarakat untuk mempermudah dan mempercepat segala kegiatan dan pekerjaan mereka. Di zaman modern seperti sekarang ini, perlu dilakukan penemuan dan pengembangan alat pengendali dari jarak jauh agar suatu pekerjaan manusia menjadi lebih cepat dan mudah. Saat ini, sistem buka tutup pintu gerbang masih banyak dilakukan dengan mendorong dan menarik pintu gerbang secara langsung atau manual dengan menggunakan tenaga manusia [1].

Berdasarkan hal tersebut maka pada penelitian ini dilakukan Desain Otomatisasi Pintu Gerbang Fakultas Tehnik UMJ menggunakan RFID atau Pasword dengan Sensor Laser Dioda yaitu sebuah ID Card Acces dan pasword, alat ini cocok diaplikasikan untuk daerah Fakultas Teknik yang dimana didalamnya dibutuhkkan keamanan akses masuk kewilayah tersebut sehingga suasana dapat terjalin dengan tenang dan teratur.

Desain Otomatisasi Pintu Gerbang Fakultas Tehnik UMJ menggunakan RFID atau Pasword dengan Sensor Laser Dioda memiliki kelebihan di bandingkan sistem yang telah ada sebelumnya, kelebihan dari sistem yang kami buat adalah sistem ini tidak menggunakan remote kontrol tetapi memanfaatkan gelombang elektromagnetik dan pasword sebagai pengkodean untuk membuka pintu gerbang, sedangkan sensor laser dioda disini sebagai pendeteksi mobil, jika kendaraan memutuskan cahaya sensor laser dioda maka pintu gerbang akan tertutup. 


\section{KAJIAN PUSTAKA DAN PENGEMBANGAN HIPOTESIS}

\subsection{Mikrokontroler ATMega8535}

Mikrokontroler ATMega8535 adalah sebuah chip yang merupakan kemasan keseluruhan dari sistem komputer dan didalamnya terdapat I/O, mikroprosesor, memory bahkan ADC. Semua intruksi pada Mikrokontroler ATMega8535 dikemas dalam kode 16-bit. Mayoritas instruksi dieksekusi dengan teknologi Reduced Instruction Set Computing (RISC) yang dilakukan dalam 1 siklus clock. Menurut M. Ari Heryanto dan Wisnu Adi P [2] kapabilitas detail dari ATMega 8535 adalah sebagai berikut:

a. Sistem mikroprosesor 8 bit memiliki kemampuan tinggi,

b. Berbasis RISC dengan kecepatan maksimal sampai dengan $16 \mathrm{Mhz}$.

c. Kapabilitas memory flash $8 \mathrm{~KB}$, SRAM sebesar 512 byte, dan Electrically Erasable ProgrammableRead Only Memory (EEPROM) sebesar 512byte yang dapat dibaca/tulis sampai 100000 kali.

d. ADC internal yang fidelitas 10 bit dengan 8 channel.

e. USART atau Portal komunikasi serial dengan kecepatan maksimal sampai dengan 2,5 Mbps.

f. Saluran I/O sebanyak 32 buah.

g. Cpu yang terdiri atas 32 register.

\begin{tabular}{|c|c|c|c|c|c|}
\hline \multicolumn{6}{|c|}{ PDIP } \\
\hline$(\mathrm{XCK} / \mathrm{TO})$ PBO & 1 & 40 & 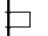 & PAO & $(A D C 0)$ \\
\hline (T1) PB1 & 2 & 39 & 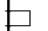 & PA1 & (ADC1) \\
\hline (INT2/AINO) PB2 & 3 & 38 & $\sqsupseteq$ & PA2 & $(A D C 2)$ \\
\hline (OCO/AIN1) PB3 & 4 & 37 & $巨$ & PA3 & (ADC3) \\
\hline$(\overline{\mathrm{SS}}) \mathrm{PB} 4$ & 5 & 36 & 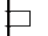 & PA4 & $(A D C 4)$ \\
\hline (MOSI) PB5 & 6 & 35 & $巨$ & PA5 & (ADC5) \\
\hline (MISO) PB6 & 7 & 34 & 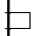 & PA6 & (ADC6) \\
\hline (SCK) PB7 & 8 & 33 & 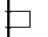 & PA7 & (ADC7) \\
\hline$\overline{\text { RESET }}$ & 9 & 32 & $\sqsupseteq$ & AREF & \\
\hline VCC & 10 & 31 & 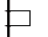 & GND & \\
\hline GND & 11 & 30 & $\sqsubseteq$ & AVCO & \\
\hline XTAL2 & 12 & 29 & $\sqsubseteq$ & PC7 & (TOSC2) \\
\hline XTAL1 & 13 & 28 & 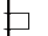 & PC6 & (TOSC1) \\
\hline (RXD) PDO & 14 & 27 & $\sqsubseteq$ & PC5 & (TDI) \\
\hline (TXD) PD1 & 15 & 26 & $\sqsubseteq$ & PC4 & (TDO) \\
\hline (INTO) PD2 & 16 & 25 & $巨$ & PC3 & (TMS) \\
\hline (INT1) PD3 & 17 & 24 & $\sqsubseteq$ & $\mathrm{PC} 2$ & (TCK) \\
\hline (OC1B) PD4 & 18 & 23 & 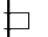 & $\mathrm{PC} 1$ & (SDA) \\
\hline (OC1A) PD5 & 19 & 22 & $\sqsubseteq$ & PCO & (SCL) \\
\hline (ICP1) PD6 & 20 & 21. & $\sqsupseteq$ & PD7 & (OC2) \\
\hline
\end{tabular}

Gambar 1 Konfigurasi pin -pin mikrokontroller ATmega8535

\subsection{Tag \& Reader Radio Frequency Identification (RFID)}

ID tag merupakan device elektronik yang didalamya terintegrasi antena dan rangkaian elektronika yang dapat menyimpan data karena dilengkapi dengan memori [3]. Memori yang terdapat pada ID tag terbagi atas sel-sel. Data Read Only seperti serial number akan disimpan oleh beberapa sel ketika tag tersebut dibuat. Sel lain juga memungkinkan untuk dapat dibaca dan ditulis secara berulangulang. Pada saat reader mengalami kontak dengan ID tag, maka akan terjadi transfer gelombang elektromagnetik. 


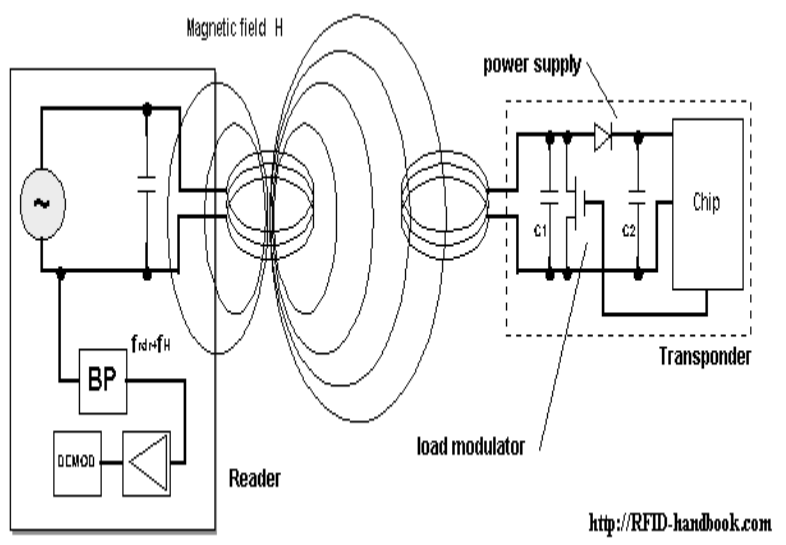

Gambar 2. Cara kerja RFID

ID tag berbasis RFID memiliki beberapa keunggulan, diantaranya yaitu ID tag tidak harus membaca garis-garis secara diagonal atau horizontal sepert barcode sehingga mampu diidentifikasi secara otomatis tanpa perlu diluruskan. Selain itu, ID tag juga memiliki kemampuan untuk diidentifikasi menembus berbagai macam objek seperti kayu, plastik, dan kertas.

RFID dapat digolongkan menjadi dua jenis berdasarkan catu daya tag yang digunakannya yaitu tag aktif dan tag positif. Tag Aktif merupakan tag yang menggunakan catu daya berupa baterai. Kelebihan dari penggunaan tag ini adalah informasi dikirimkan dalam jarak yang lebih jauh dan mengurangi daya yang diperlukan oleh pembaca RFID, sedangkan kelemahan dari tipe tag ini rangkaiannya komplek sehingga memiliki ukuran yang lebih besar dan harga yang mahal. Semakin banyak fungsi yang dapat dilakukan oleh ID tag maka akan membuat ukuran ID tag semakin besar karena rangkaiannya semakin komplek.

Tag Pasif merupakan tag yang menggunakan catu daya dari medan yang dihasilkan oleh pembaca RFID. Tag pasif ini memiliki beberapa kelebihan yaitu harganya jauh lebih murah, memiliki rangkaian yang lebih sederhana sederhana sehingga ukurannya kecil dan lebih ringan. Selain memiliki kelebihan, tag ini juga memiliki kelemahan yaitu informasi hanya dapat dikirimkan dalam jarak dekat dan ID tag membutuhkan daya tambahan yang harus disediakan oleh RFID.

Umumnya, tag atau transponder pada sistem RFID ditempelkan pada suatu objek. Masingmasing tag dapat membawa informasi seperti model, serial number, tempat perakitan, warna, dan data lainnya dari objek tersebut.

Proses identifikasi objek dapat dilakukan ketika RFID reader yang kompatibel menghasilkan medan magnet yang kemudian dilalui oleh tag sehingga terjadi transmisi informasi dari tag ke RFID reader.

Sirkuit rangkaian pada ID tag membutuhkan sumber tenaga listrik agar dapat bekerja. Sumber tenaga listrik ini diperoleh dari pengiriman energi listrik melalui medan elektromagnet dari reader ke ID tag. Beberapa ID tag dapat dibaca oleh reader dalam jarak 10 meter atau lebih dalam waktu yang bersamaan.

ID tag pasif tidak mempunyai power supply sendiri. Dalam mengirimkan respon balik, ID tag hanya membutuhkan induksi listrik pada antena yang disebabkan oleh masuknya frekuensi radio scanning.

Sinkronisasi bit pada pengiriman data dari ID tag ke reader menggunakan encoding Manchester. Pada encoding Manchester ini, terjadi perubahan transisi ditengah interfal dimana bit " 0 " menunjukkan perubahan yang terjadi dari positif ke negatif, sedangkan bit "1" menunjukkan perubahan yang terjadi dari negatif ke positif. Respon dari RFID pasif biasanya hanya berupa nomor identitas sehingga cukup sederhana karena powernya yang kecil dan biaya yang murah. Jarak yang dapat dijangkau ID tag pasif adalah bervariasi dari $10 \mathrm{~mm}-6$ meter. 
Berbeda dengan ID tag pasif, ID tag aktif diharuskan mempunyai catu daya tersendiri yang dibutuhkan untuk menjangkau jarak yang lebih jauh. ID tag aktif memiliki memori yang lebih besar sehingga memungkinkan untuk bisa menyimpan berbagai macam informasi. ID tag aktif ini bisa menjangkau jarak kurang lebih sampai 10 meter dengan umur baterai bisa bertahan lama sampai beberapa tahun [4-6].

\subsection{Motor DC}

Motor DC merupakan alat yang mampu mengubah daya listrik searah (DC) menjadi daya mekanik. Pada motor DC, gaya yang menggerakkan penghantar akan timbul ketika penghantar tersebut dialiri listrik dan terletak diantara kutub utara dan kutub selatan magnet.

Kumparan dalam medan magnet dengan arah arus dari kedua sisinya berlawanan akan menyebabkan arah gerak terhadap putarannya menjadi berbeda sehingga menghasilkan gaya gerak putar atau kopel. Besar kopel akan bergantung pada besar arus dan gaya magnet. Semakin besar arus menyebabkan kopel semakin besar maka akan semakin besar kopelnya dan juga ketika gaya magnetnya makin kuat maka kopelnya akan semakin berat. Jika kumparan diletakkan diantara kutub magnet yang sedang berputar, maka pada kumparan tersebut akan timbul suatu tegangan dari luar yang disebut ggl (gaya gerak listrik) lawan. Besar kecilnya atau nilai ggl lawan akan dipengaruhi oleh tahanan jangkarnya [7]

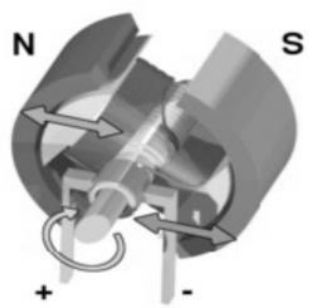

Gambar 3. Bagian motor arus searah

\subsection{Sensor Laser Dioda}

Sensor merupakan tranduser berfungsi untuk mengubah besaran magnetis, mekanis, kimia, sinar, dan panas menjadi arus listrik dan tegangan. Sensor sering dimanfaatkan sebagai pendeteksi ketika melakukan pengendalian maupun pengukuran.

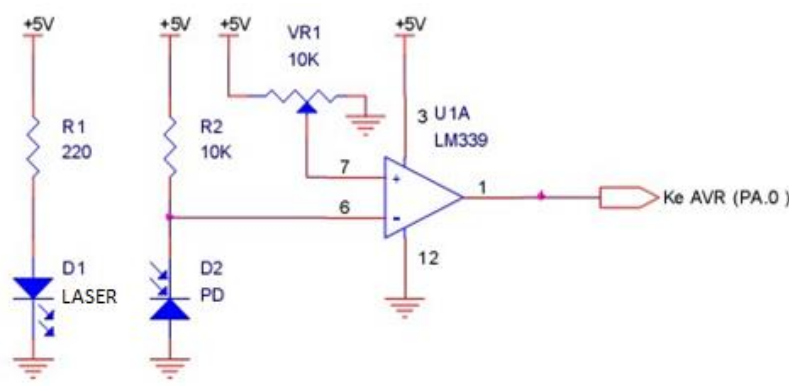

Gambar 4. Rangkaian laser photodiode

\subsection{Keypad}

Keypad merupakan suatu unit papan tombol digunakan sebagai sarana masukan pada sistem. Pada sistem ini, terdiri dari 16 tombol masukan yang terdiri dari angka (0 sampai 9) dan beberapa tombol lainnya seperti A,B,C,D, ${ }^{*}$, dan \#. 


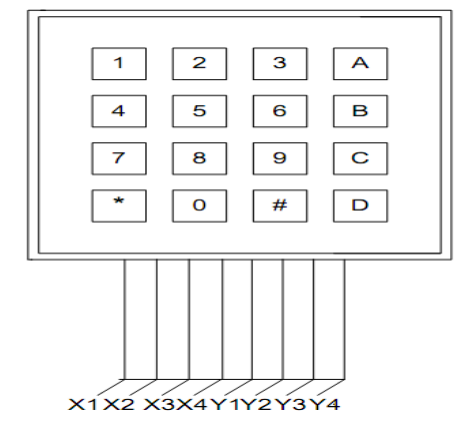

. Gambar 5. Keypad

Tombol keypad memiliki penyemat yaitu X1, X2, X3,X4 untuk baris dan Y1, Y2, Y3, Y4 untuk kolom sehingga keseluruhan tombol yang dapat ditangani adalah $4 \times 4$ atau 16 tombol.

\subsection{LCD (Liquid Crystal Display) LMB162A 2 x 16 Character}

LCD berguna untuk menampilkan pesan yang tersimpan di alamat label pesan LCD, sebagai keluaran waktu pada mikrokontrol parallax BS2P40. LCD mempunyai banyak variasi ukuran, tapi dalam penyusunan penelitian cukup yang dibutuhkan adalah LCD dengan ukuran $2 \times 16$ (dua baris enam belas kolom). Yang perlu diperhatikan dalam hal ini adalah:

1. LCD selalu pada kondisi write (tulis) sehingga agar tidak mengeluarkan data dengam kondisi read (baca) maka kaki R/W dihubungkan ke ground.

2. Akses ke LCD dilakukan dengan menggunakan mode I/O biasa dan tidak memakai mode bus meskipun LCD terhubung dengan jalur bus.

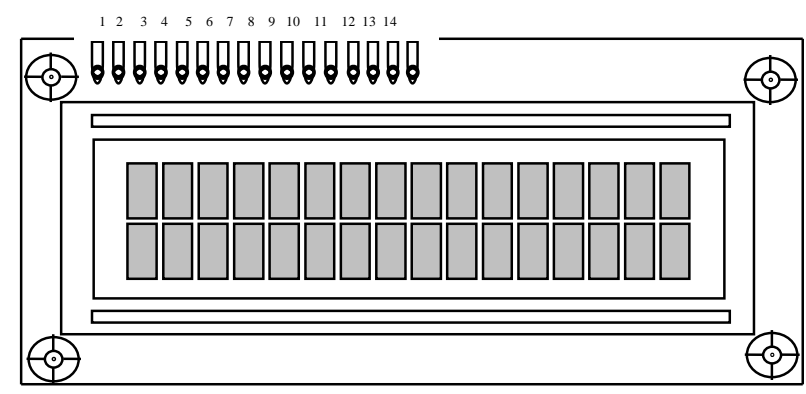

Gambar 6. Pin konfigurasi LCD (LMB162A)

\section{METODE PENELITIAN}

\subsection{Perancangan dan Pembuatan Perangkat Keras}

Sistem yang digunakan dalam pembuatan alat "Desain Otomatisasi Pintu Gerbang Fakultas Tehnik UMJ menggunakan RFID atau Pasword dengan Sensor Laser Dioda" Secara umum dibagi menjadi beberapa bagian yaitu :

1. Mikrokontroller ATmega 8535

Mikrokontroler AVR Atmega8535 merupakan suatu mikrokontroler 8 bit yang menggunakan arsitektur Reduced Instruction Set Computer (RISC). Mikrokontroler AVR ATmega8535 ini bekerja secara satu siklus pengiriman data yang memberikan keluaran sebesar 1MIPS per MHz.

2. Driver Motor DC

Driver Motor DC berfungsi sebagai komponen yang dapat menggerakan mekanik agar dapat membuka dan menutup pintu gerbang sehingga pengendara dapat melalui atau memasuki dan keluar dari lingkungan setempat. 
3. LCD (Liquid Crystal Display)

Berfungsi sebagai komponen yang dapat menampilkan pembacaan Acces warga yang berhak memasuki area perumahan tersebut.

4. RFID (Radio Frequency Identification Device)

RFID (Radio Frequency Identification Device) merupakan proses identifikasi suatu objek dengan memanfaatkan frekuensi transmisi radio. Frekuensi radio ini berfungsi untuk membaca informasi dari RFID tag atau transponder (Transmitter Responder) yang selanjutnya disingkat menjadi ID tag.

5. Sensor Laser Dioda

Berfungsi untuk mendeteksi kendaraan mobil yang telah memasuki area Fakultas Teknik, apabila kendaraan telah melewati batas masuk area maka secara otomatis sehingga pintu gerbang akan kembali menutup.

6. Tombol Keypad

Digunakan sebagai saranan untuk mengimputkan pasword pada Mikro Kontrol yang nantinya akan di proses untuk membuka pintu gerbang.

7. Power supply

Berfungsi sebagai catu daya untuk mengaktifkan seluruh rangkaian buka tutup pintu gerbang dengan tegangan input sebesar 5 Volt.

8. Tombol On/Off

Tombol disini sebagai sarana masukan pada sistem yang masih belum terdaftar melalui kepemilikan ID Card Acces atau Pasword, maka diperlukan satu unit papan tombol.

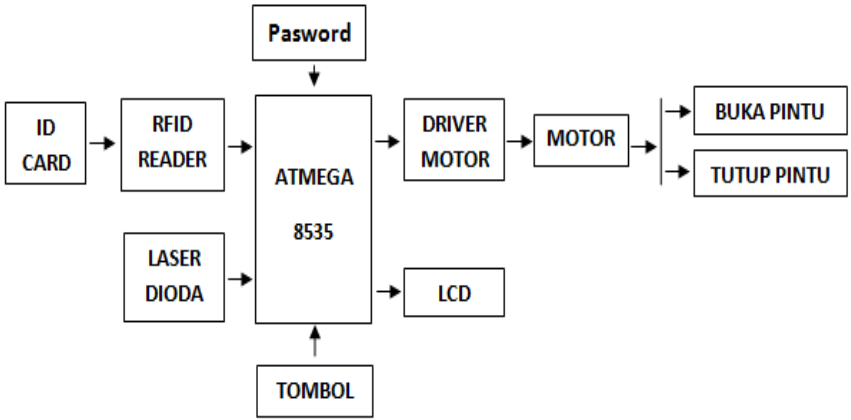

Gambar 7. Diagram Blok Alat yang Dibuat

\subsection{Perancangan Mekanik}

Perancangan mekanik pada alat ini terdiri dari beberapa bagian :

1. Motor DC yang digunakan untuk membuka dan menutup pintu gerbang dengan bantuan gearbox yang terbuat dari plastic.

2. Pintu gerbang buka tutup pada simulasi ini terbuat dari akrilik atau triplek yang disesuaikan dengan motor yang digunakan

\subsubsection{Mikrokontroller ATmega853}

Mikrokontroler AVR ATmega8535 berfungsi sebagai pengendali utama pada perangkat keras. Saat ada kartu RFID tag yang mendekat pada RFID reader, integrated circuit yang ada didalam tag akan dibangkitkan karena pengaruh gelombang elektromagnetik sehingga ID yang ada di dalam tag tersebut akan terbaca oleh RFID reader. Selanjutnya, AVR ATmega8535 memproses data yang terbaca oleh reader untuk disimpan di memori eksternal EEPROM 24C08. Masing-masing kartu memiliki data sebesar 22 byte atas terdiri dari 16 byte data ID tag. Selain itu, sistem ini juga memerlukan power supply yang dapat memberikan 
tegangan sebesar 5 Volt DC. Rangkaian sistem minimum telah siap mendapat sinyal digital di port A.

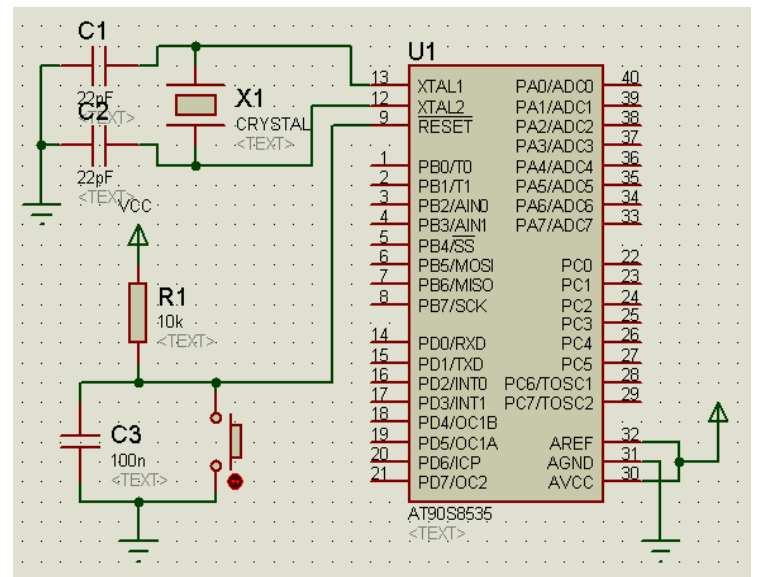

Gambar 8. Rangkaian sistem minimum ATmega8535

\subsubsection{Aktuator Motor (DC)}

Motor DC yang digunakan adalah motor DC 6 Volt dengan skema rangkaian dapat dilihat pada gambar di bawah ini:

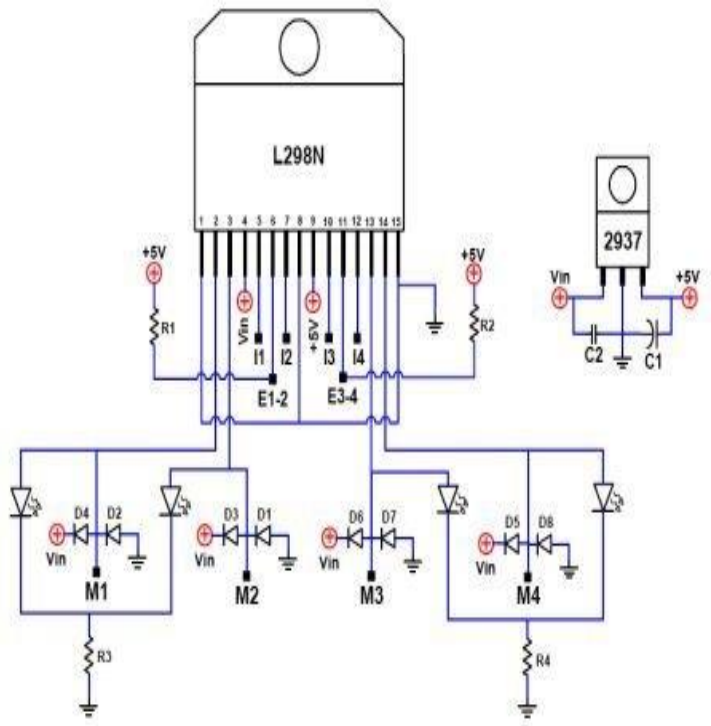

Gambar 9. Rangkaian driver motor (DC)

\subsubsection{RFID Reader dan Tag RFID}

Pada penelitian ini, RFID reader yang digunakan adalah RFID reader ID-12. RFID merupakan modul utama yang berfungsi untuk membaca data berupa nomor ID tag yang ada pada tag. RFID reader ini memiliki antena internal sehingga tidak memerlukan antena eksternal. Untuk mengaktifkan RFID ini diperlukan daya sebesar 5 Volt. Jarak pembacaan RFID reader ID-12 ke ID tag kurang lebih hingga $12 \mathrm{~cm}$ dengan format data output adalah ASCII. Setiap ID tag dapat menyimpan data sebesar 16 byte dimana dalam 8 bit akan mempresentasikan satu karakter dalam ASCII. Proses pengiriman data, akan selalu diawali dengan start bit dan diakhiri dengan stop bit. 


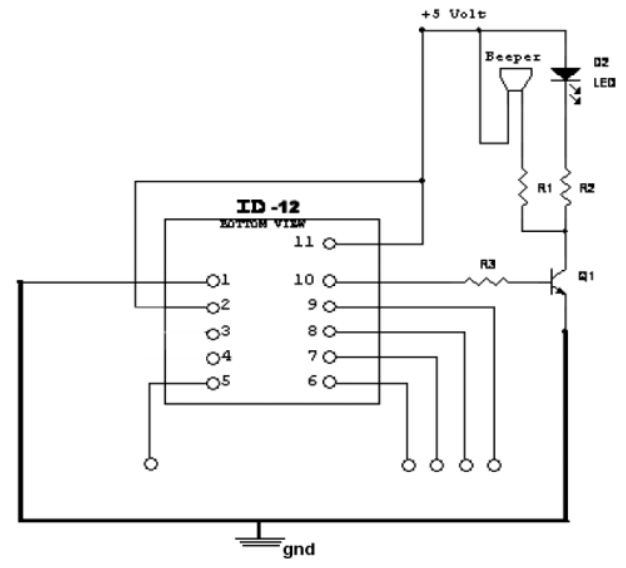

Gambar 10. Rangkaian RFID

\subsubsection{Sensor Laser Dioda}

Rangkaian sensor cahaya ini bertugas untuk membaca nilai $\mathrm{O}$ dan I untuk menutup pintu gerbang tersebut, adapun rangkaianya dapat dilihat pada gambar dibawah ini :

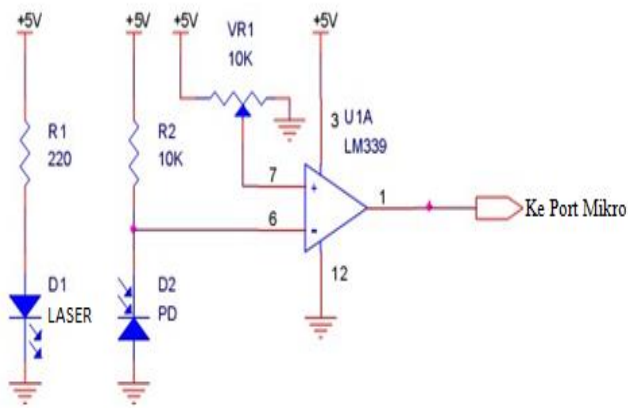

Gambar 11. Rangkaian sensor laser dioda

\subsubsection{Rangkaian LCD Display}

LCD (Liquid Cristal Display) adalah perangkat teknologi elektronika untuk menampilkan pesan/ data yang diinstruksikan oleh mokrokontroler. Dari gambar 3.6 di bawah ini data yang ditampilkan adalah yang ditulis (W) untuk dikirim mikrokontrol parallax BS2P40, sehingga karena untuk menampilkan pesan maka pin 5 yang digunakan untuk memilih instruksi Read atau Write, harus digroundkan agar tidak mengeluarkan kondisi baca.

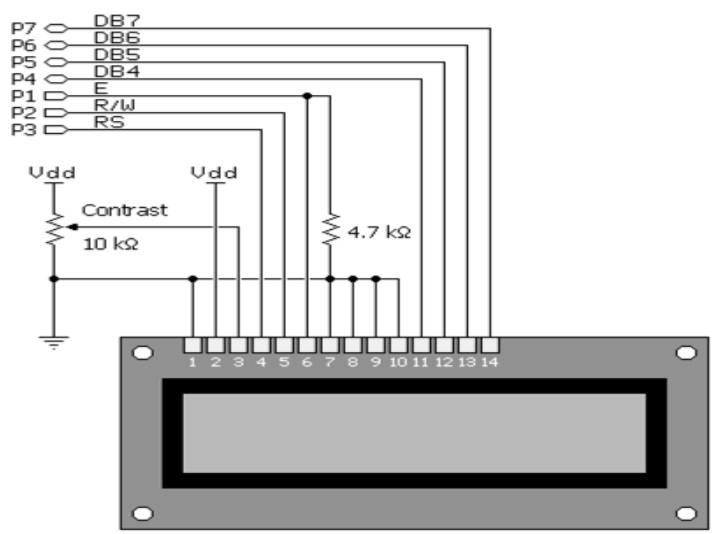

Gambar 12. Rangkaian LCD LMB162A 2 x16 character 


\subsection{Perancangan Perangkat Lunak}

Sistem kerja dari program sistemditunjukan pada flowchart berikut:

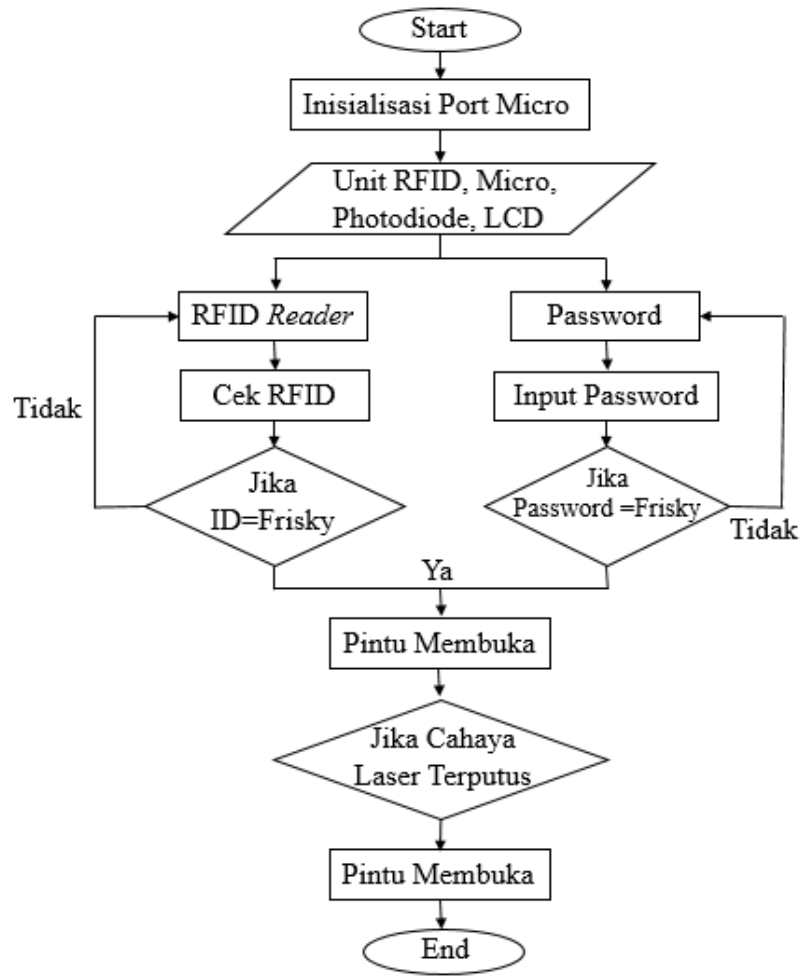

Gambar 13. Flowchat Kerja Alat

\section{HASIL DAN PEMBAHASAN}

Pada penelitian ini dilakukan pengujian alat yang dilakukan untuk mengetahui kondisi sistem apakah telah bekerja sesuai dengan perencanaan atau belum. Pungujian alat dilakukan dalam dua tahapan yaitu tahap pengujian alat yang dilakukan secara terpisah, dan tahap pengujian sistem secara keseluruhan.

Pengujian yang dilakukan pada penelitian ini yaitu:

1. Pengujian mikrokontroler ATMega 8535

2. Pengujian perangkat masukan :

- RFID

- Sensor Laser Dioda

- Keypad

3. Pengujian perangkat keluaran :

- Display LCD

- Driver Motor

4. Pengujian keseluruhan Sistem

Setelah pengetesan dari beberapa bagian rangkaian mengenai sistem ini, selanjutnya adalah pengetesan rangkaian secara keseluruhan yang bertujuan untuk mengevaluasi dan uji coba sistem yang telah dibuat, apakah perangkat ini sudah berjalan sesuai yang diinginkan atau sebaliknya.

Prosedur pengujian untuk perangkat ini adalah merangkai rangkaian seperti pada skema diagram blog pada bab III gambar 3.1, dari rangkaian yang telah dirangkai diberi tegangan pada keseluruhan rangkaian untuk mengaktifkan semua sistem, setelah semua rangkaian sistem ini aktif maka LCD akan menampilkan tulisan

"ENTER ID" dan LED pertama pada Reader akan menyala, dengan demikian pengetesan bisa segera kita lakukan dengan cara mendekatkan Tag RFID pada RFID Reader, jika Tag sudah terdeteksi oleh RFID 
Reader maka LED kedua pada RFID Reader akan menyala menunjukan bahwa Tag RFID sudah terbaca oleh Reader yang menghasilkan data inputan berupa angka unik dari Tag RFID, dari angka tersebut dikirim kemikrokontrol berupa data digital dan dikonversi kedata analog melalui serial ke mikrokontrol yang dimana data tersebut diprogram untuk memberikan perintah pada driver motor kapan motor akan bergerak untuk membuka pintu gerbang.

Dari hasil pengujian rangkaian keseluruhan, didapatkan hasil bahwa rangkaian dan alat dapat beroperasi sesuai dengan perintah yang telah didownload dalam Mikrokontroller ATmega8535..

Tabel 1 Percobaan Tag RFID pada RFID reader atau password

\begin{tabular}{ccccc}
\hline No & Percobaan & Nama & Buka pintu & $\begin{array}{c}\text { Pintu } \\
\text { gerbang }\end{array}$ \\
\hline 1 & & Mr. Frisky & Berhasil & Berhasil \\
2 & I & Mr. Nicko & Berhasil & Berhasil \\
3 & & Mr. Panca & Berhasil & Berhasil \\
4 & & Orang Asing & Gagal & Gagal \\
\hline 1 & & Mr. Frisky & Berhasil & Berhasil \\
2 & \multirow{2}{*}{ II } & Mr. Nicko & Berhasil & Berhasil \\
3 & & Mr. Panca & Berhasil & Berhasil \\
4 & & Orang Asing & Gagal & Gagal \\
\hline
\end{tabular}

\section{KESIMPULAN}

Berdasarkan hasil pengujian alat dan analisis yang telah dilakukan, maka dapat disimpulkan bahwa :

1. Sensor RFID bekerja sesuai dengan yang diharapkan. Terbukti bahwa sistem simulasi buka tutup gerbang dapat berjalan dengan baik ketika gerbang membuka dan menutup ketika melewati Photodiode sesuai waktu yang ditentukan, serta "ID denided" disaat ID Card Acces tidak terdaftar.

2. Rangkaian driver pada motor bekerja dengan baik sehingga motor A dan B bergerak dengan gerakan sesuai yang diharapkan, dan alat dapat bekerja secara otomatis sesuai keinginan.

3. LCD dapat menampilkan data sesuai yang telah diprogram yaitu menampilkan nama pemilik ID Card Acces.

\section{REFERENSI}

[1] Ngafifi, M., 2014, Kemajuan Teknologi dan Pola Hidup Manusia dalam Perspektif Sosial Budaya, Jurnal Pembangunan Pendidikan: Fondasi dan Aplikasi, Vol. 2, No. 1, 33-47.

[2] Heryanto, A. dan Wisnu, A., 2008, Pemrograman Bahasa C untuk Mikrokontroler ATMEGA8535, Yogyakarta.

[3] Iswanjono dan Natalianto, N., 2017, Sistem Presensi Perkuliahan Berbasis Radio Frequency Identification, Media Teknika Jurnal Teknologi Vol.12, No.1, 93-103.

[4] Hunt, V. D., Puglia, Albert., dan Puglia, Mike. 2007. RFID - A Guide to Radio Frequency Identification, John Wiley \& Sons.

[5] Golburg, Joseph, 2005: RFID Evaluation Kit, Adilam Electronic.

[6] Sweeny II , Patrick J, 2005, RFID for Dummies, Wiley Publishing Inc, Indiana

[7] Nugroho, G.A., 2006, Sistem Power Window pada Suzuki Baleno, Universitas Negeri Semarang, Semarang. 


\section{BIOGRAFI PENULIS}

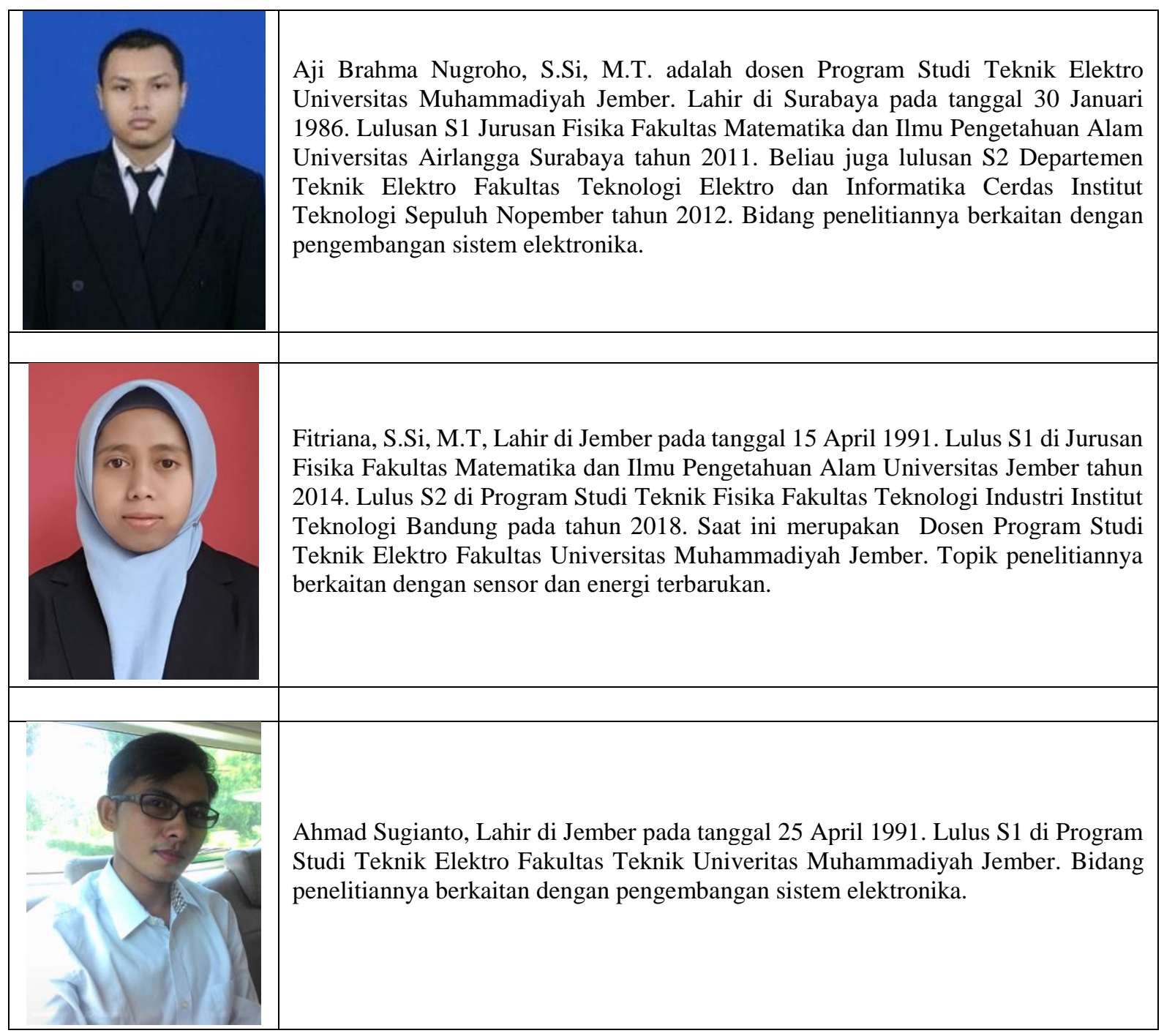

